\title{
Psychological Well-Being and Sexual Behaviour of South African Teenage Mothers: An Overview
}

\author{
J.G. Kheswa \\ T. J. Pitso \\ Department of Psychology, University of Fort Hare, Private Bag X1314, Alice, 5700 \\ Email jkheswa@ufh.ac.za

\section{Doi:10.5901/mjss.2014.v5n10p563} \\ Abstract \\ Teenage motherhood has counted against the educational success of girls in South Africa. Psychologically, such youth end up \\ being depressed and experience difficulty completing immunization regimes, forming mother-infant bond and achieving self- \\ actualization. This research paper intends to investigate the psychological well-being and sexual behaviour of teenage mothers \\ with specific reference to their relationship with parents and sexual partners, and the impact they have on their children. \\ Findings are that lack of knowledge and skills of motherhood leads to alcohol consumption during breastfeeding which could \\ lead to Fetal Alcohol Syndrome (FAS) in babies. Furthermore, teenage mothers are demotivated and feel embarrassed to seek \\ sexual health care, resulting in them being exposed to risky sexual behaviour (e.g. HIV/AIDS). The recommendations are that; \\ to improve their psychological well-being, sex-education and counselling, should be provided, at home, schools and health \\ centres.
}

Keywords: Psychological well-being, Teenage mothers, Sexual behaviour, Emotional abuse, Maltreatment, Poverty

\section{Introduction}

Teenage motherhood emerged as a result of high teenage pregnancy in the 1960s (Furstenburg, 2007; Luker, 1996; Wong \& Checkland, 1999) and from sociological perspective, it is caused by social disorganizations and culture (Wilson, 1987). In South Africa, the prevalence of teenage motherhood increased with age between 2009 and 2011, and 10, 2\% among the 19 year old girls reported to have given birth as compared to only 0,3\% among the 13 year old girls (Ngcwayi, 2013). With approximately 30\% of teenage mothers in South Africa (Willan, 2013), in 2011, in KwaZulu- Natal, 10595 teenage pregnancies were reported by the Department of Education (Mdletshe, 2013). In the Eastern Cape, which is the poorest, the statistics shows that 5183 were pregnant in 2012, and the high rate of teenage pregnancy and subsequent teenage motherhood had been reported in the rural areas; 857 in Libode, 481 in Dutywa and 422 in Lusikisiki (Ngcwayi, 2013). Against this background, this paper intends to investigate the psychological well-being of teenage mothers with specific reference to their relationship with parents and sexual partners. Furthermore, the researcher will elucidate the link between child neglect and poor self-regulation in the well-being of their offspring. Finally, recommendations in helping teenage mothers will be discussed.

\section{Methodology}

de Vos, Fouche, Strydom and Delport (2011) are of the view that the reviewing of relevant literature is important and should aim at contributing at a clearer understanding of the nature and meaning of the problem that has been identified. Based on that, it is crucial that the researcher must ensure that nobody else has conducted the equivalent research. According to Mouton (1996), review of literature provides guidelines and suggests design to be used in the study. Review of literature helps the researcher to get a deeper insight and more knowledge about the research problem (de Vos et al., 2011; Mouton, 1996). For this research paper, the related research studies, recent and classic academic journals, books and internet sources have been reviewed to get an overview and address the psychological well-being of South African teenage mothers and its effects on children.

\section{Psychological Well-Being}

Diener and Lucas (1999), conceptualized psychological well-being as a broad construct, which encompasses four distinct components; (i) pleasant effect or positive well-being (e.g. mental health, happiness, elation), (ii) unpleasant effect or psychological distress( depression, stress, shame, guilt, anger, anxiety, sadness), (iii) life's satisfaction(e.g. global evaluation of one's life) and (iv) situation satisfaction (e.g. family, work, health, finances, health). According to Ryff and Keyes (1995), the Ryff Scales of psychological well-being is defined as a dynamic concept that includes subjective, social, and psychological dimensions as well as health-related behaviours. Furthermore, it is theoretically grounded and 
specifically focuses on measuring the following facets of multiple psychological well-being; namely; self-acceptance, establishment of quality ties to others, a sense of autonomy in thought and action, the ability to manage complex environments to suit personal needs and values, the pursuit of meaningful goals and a sense of purpose in life, and continued growth and development as a person.

According to Markway and Markway (2011) most of the teenage mothers are faced with a challenge of accepting themselves due to their negative upbringing which could have an impact on their self-value and self-acceptance. As a result, they become victims of exploitation, premature sexual intercourse and further unwanted pregnancy. In a study conducted in Lesotho by Lehana and van Rhyn (2003), it was established that teenage mothers were not emotionally, cognitively and socially ready for motherhood. Sodi (2009), in another qualitative study, in Limpopo province, teenage mothers reported being self-critical and angry with themselves as they realized that their future would not be as bright as it would have been the case, when they were still single.

At school when there is a lack of emotional attachment and bonding between educators and teenage mothers as their loco-parentis, several studies show that they may project anger towards their children (Papalia et al, 2009). Macleod (2003) found that sometimes teen mothers have fear participating in class discussions for instance during "Life Orientation" programmes. Owing to their faulty reasoning and thinking, when topics like 'teenage pregnancy' arise, the teen mothers become particularly uncomfortable that everybody is talking about their situation (Grant \& Hallman, 2006). Psychologically, such youth end up being depressed and experience difficulty completing immunization regimes, forming mother-infant bond, and completion of breastfeeding period. In other words, they feel prejudiced, isolated and rejected.

Research by Holborn and Eddy (2011) found that the poor socio-economic background and lack of necessary skills of the teenage mothers impede them to be autonomous and gain a sense of independence in order to face everyday challenges. As a result, they feel inadequate and subservient to their sexual partners to an extent that they are unable to express their inner feelings and emotions (Casad, Marcus-Newhall, Nakawaki, Kasabian, \& LeMaster, 2012; Dunkel, 2011). Given that females are subscribed to certain cultural roles in many societies, the psychological wellbeing of majority of teenage mothers deteriorates (Impett \& Peplau, 2003). Notably, Chigona and Chetty (2008) found that majority of black teenage mothers in South Africa lack necessary skills in turning the so called crisis or personal mistakes into a life learned experience which might impede the prognosis of intergenerational vicious-cycle of teenage motherhood. Previous scholars documented that when teenage girls lack support and encouragement from society to claim their sexual identity as part of their human rights; they feel marginalized and expose themselves to risky sexual behaviours (Koen, 2009; Van Eijk, 2007). Risk sexual behaviour includes being sexually active, having multiple sexual partners, practicing unsafe sex, sex while drunk, usage of drugs, sexual promiscuity and sexual or partner violence (Dunkle, Jewkes, Nduna, Levin, Jama, Khuzwayo, Koss \& Duvvury, 2006; Richter, Komárek, Desmond, Celentano, Morin, Sweat \& Coates, 2013). Due to stress, to cover their emotional inadequacy, they develop a tendency to drink alcohol, sleep with multiple sexual partners and feel the need to prove that they are able to have children before marriage as a way of attaining adult status (Gustafsson \& Worku, 2002; Jewkes et al., 2009) which impairs their psychological wellbeing. This calls for teenage mothers to be aware of who they are so that they can understand their goals and their significance in life but in most cases their lack of proper education and appropriate life skills forbids them to live their expected life (Compton \& Hoffman, 2013).

\section{Factors Contributing to Teenage Motherhood}

As hypothesized by Brook, Morojele, Zhang and Brook (2006), in figure 1, teenage mothers who come from poor families tend to be adversely affected by unemployment of parents, and develop vulnerable personalities with low level of morality and values, join deviant peers who may expose them to further risky -taking behaviours, especially when they have given birth during early adolescence. The implication of this hypothesis is that the more teenage mothers disregard the parental guidance, it is most likely that they may be pregnant again, drink alcohol and be prone to sexual- victimization. In a quantitative study carried out at War Memorial Clinic, Nkonkobe Muinicipaity, in the Eastern Cape, Pitso (2013), found that of the 106 respondents, $26.4 \%(\mathrm{~N}=28)$ indicated that they stayed with both parents, while $73.6 \%(\mathrm{~N}=78)$ displayed that they stayed with single parent, mother and step-father, father and step mother, aunt or uncle or boyfriend. It is clear that when parents are not available for the emotional support to their daughters, chances of teenage pregnancy and subsequent motherhood becomes uncontrollably higher. Another factor which is inextricably linked to risky sexual behaviour is homelessness or orphanhood that could be experienced by teenage mothers. Homelessness coupled with unemployment due to lack of educational skills, further complicate the lives of teenage mothers to such an extent that they may be trapped to transactional sex (Hunter, 2007; Umberson, Pudrovska \& Reczek, 2010). Woan, Lin and Auerswald (2013), found that girls who are being recruited to human trafficking are those without stable families or whose parents have died. Furthermore, due to lack of ignorance, sexually active girls end up experiencing unplanned pregnancy 
and subsequent motherhood. They change birth -control methods and practice unprotected sex (Ziyane \& Ehlers, 2006). For example, in a qualitative study conducted in Nyanga, a black township in Cape Town, Mkhwananzi (2010) found that the respondents were adamant to use contraceptives and cited that they side- effects. For instance, when asked about birth control methods, they responded as follows:

I used to take the pill but it made me sick, dizzy and vomiting and so I changed to the injection. . I I became pregnant because I did not go to renew the injection. I forgot because I lost my card and so I did not know my date ... (Gloria, 21 years old).

[When] I became pregnant I was not on any contraceptive but I was planning to start using the injection sometime but then I got pregnant ... I knew about contraceptives but I did not want to take them before because I did not like them . . . I just do not like them and my boyfriend did not want to wear a condom. (Yokazi, 19 years old)

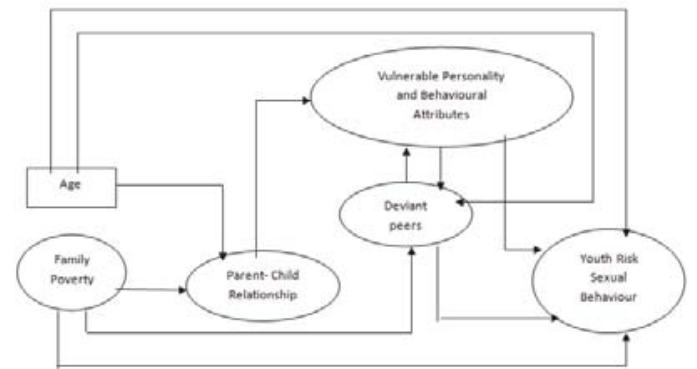

Figure 1: Hypothesized pathways to risky sexual behaviour: Adapted from Brook, Morojele, Zhang and Brook: 2006

Recent research by indicates that many of the negative outcomes of teenage motherhoods, such as low educational achievement and poverty, precede rather than stem from early parenthood (Coley \& Chase-Lansdale, 2009; Holborn \& Eddy 2011; Panday, Makiwane, Ranchod \& Letsoala, 2009). For example, Mothiba and Maputle (2012) on factors contributing to teenage motherhood in Limpopo Province in South Africa found out that majority of girls who become pregnant come from households whose parents are unemployed and are unable to further the studies of their children.

\section{Relationship between Teenage Mothers and Their Parents}

A healthy parent -teenager relationship has features of reciprocal caring and commitment, open and honest communication, clear and congruent expectations and emotional security and expressiveness (Carr, 2011; Saddock \& Saddock, 2003). However, in many black families in South Africa, parent- teenager relationships lack these relational features especially when the daughter has become pregnant out of wedlock (Vlassoff, Shearer, Walker \& Lucas, 2008). Family or parental support is therefore crucial to foster psychological well-being for it mediates commitment, confidence, adjustment and the self- view of teenage mothers as competent (Koen, van Eeden \& Rothmann, 2013). However, Theron and Dunn (2006) found that owing to overwhelming discontent and discrimination from the family, some teenage mothers may choose to give their children for adoption and it becomes worse when the teenagers have been impregnated by married men or their sexual partners denied the pregnancies. According to Madhavan, Harrison and Sennott (2013), other aggravating situation to parents could be young men who cut contacts with their daughters and pay damages "inhlawulo" which is common in many African communities to legitimize a non-marital pregnancy. From psychopathological viewpoint, such youth may therefore, experience disenfranchised grief, and suffer from a sense of worthlessness. Their stress- level is likely to surmount due to general family dysfunctioning based on poor problemsolving skills, poor communication, lack of affective responsiveness and -involvement and unclear parental roles as described by McMaster Model of Family Functioning (Epstein, Baldwin \& Bishop, 1983).

\section{Relationship between Teenage Mothers and Their Sexual Partners}

The relationship between teenage mothers and their sexual partners is characterized by many trajectories ranging from intimate partner violence, cohabitation, sexual abuse to poverty. Jewkes, Morrell and Christofides (2009) assert that in South Africa among communities embracing culture and tradition, gender hierarchy or patriarchy and males' perception of what it means to be a man, contribute to sexual aggression of males and devaluing of the dignity of vulnerable women by being violent and less agreeable to negotiate safe sex with their partners- the stereotype that is in contrast with what feminist theory advocates. In other words, for as long as these teenage mothers are financially dependent on their sexual partners, their self-esteem will be impaired. Our point of view is cemented by Kreager, Matsueda and Erosheva (2010) and Olley (2006), whose research studies documented that when teenage mothers are living below poverty line despite receiving the child support grant from the state, they fail to exercise their autonomy for fear of physical abuse. According to Deci and Ryan (2006), autonomy refers to setting of achievable goals, having sound decision making skills irrespective 
of negative pressures from the peers and the people around.

Drawing from resilience theory and the self-determination theory, once teenage girls have moved in with their sexual partners, their future aspiration diminish. Thus, cohabitation. Cohabitation refers to the informal dwelling or staying together of the unmarried couples (Dixon-Mueller, 2008), and in developing countries, it is fuelled by poverty, domestic violence and lack of emotional connectedness with parents (Koen 2009). Such teenagers may ignore going to school, and involve themselves in unsafe sex, which in turn may lead to unintended pregnancies (Bhana, Morrell, Shefer, \& Ngabaza, 2010). Previous research studies (Chigona \& Chetty , 2008; Panday et al., 2009), reveal that there is lower rate of return for those who re-register, and a significantly lower rate of completing Grade 12, and the longer the teenage mothers stay away from education, the less likely it is that they will return. For example, in a study conducted in rural setting of KwaZulu- Natal, South Africa by SALDRU UCT (2009), teenage mothers were: $2 / 3$ of a grade behind their peers, 20 percentage points less likely to matriculate, and 25 percentage points more likely to drop out of school.

Furthermore, it becomes evident that when the psychological wellbeing of teenage mothers languish because of hardship experienced in cohabitation, substance abuse and sexually transmitted infections, including HIVIAIDS are likely.

\subsection{Substance abuse}

According to Louw and Louw (2007), lack of knowledge and skills of motherhood can lead to alcohol consumption during breastfeeding which could lead to Fetal Alcohol Syndrome (FAS) and babies who are born with FAS have defects such as microcephaly (small head) and malformations of the heart, limbs, joints and face. Owing to enormity of social challenges, teenage mothers become susceptible to drinking alcohol, smoking dagga and using drugs and due to contaminated milk which lacks nutrients, children may have conditions such as cerebral epilepsy, poor eye -hand coordination, deafness and autism, and intelligent quotient (IQ) below 70 that could be responsible for increased impulsivity and anti-social personality (Pastorino \& Doyle-Portillo, 2011).

\subsection{Sexually transmitted infections and HIVIAIDS}

As compared to non-abused mothers, emotionally abused adolescent mothers tend to initiate sex earlier, experience sex with much older partners, and engage in riskier, more frequent, and promiscuous sexual activities (Nzouankeu, 2010). In a review of South African research, Eaton, Flisher and Aaro (2003), found that $50 \%$ to $60 \%$ of sexually active teenage mothers did not use condoms and 75\% experienced sexually transmitted infections. Teenage mothers tend to show poor psychosocial and health outcomes when discovering that they are HIV- positive. In their avoidant coping mechanism, they are most likely to disengage themselves from interacting with significant others drink alcohol and fail to adhere to anti-retroviral treatment (ARV) (Louw \& Louw, 2007; Kotze, Visser, Makin, Sikkema \& Forsyth, 2013). Once under the influence of alcohol, they may have tendencies to deny their health status and continue to practice unsafe sex (Bryan, Kagee., \& Broaddus, 2006). In that process their distorted psychological well-being may increase the viral load, drop the $\mathrm{Cd} 4$ count and eventually contribute to the resistance of the ARVs (WHO, 2006)

Consequently, Formby, Hirst, Owen, Hayter and Stapleton (2010), found that they are demotivated and feel embarrassed to seek sexual health care, including access to services such as counselling and family planning as majority of them view the health workers as people who lack confidentiality

\section{Impact of Psychological Well-Being of Teenage Mothers on Children}

According to IRIN Africa (2011) teenage mothers are faced with enormous pressure; to do school work, nurture their babies and be self-reliant. When the child falls sick the teen mother has to take the baby to hospital; and if the child has to be admitted in the hospital for a period of time, the teen mother has to miss classes. In a qualitative research study conducted in Cape Town among high school teenage mothers in black-township, Chigona and Chetty (2008), found that all 10 girls who participated voluntarily in the study during the focus group expressed that they do not have enough time to complete their homework and to study at home. When they return from school, their relatives who take care of the children want to be free of the child-care chores and the babies also want the attention from their mother when they return from school.

Teenage mothers who grew up with history of maltreatment tend to be uninvolved in the welfare of their children and exhibit clinical levels of mental health symptoms irrespective of their geographical locations and are prone to poor antenatal health, and their babies malnourished and at higher risk of death in infancy (Valentino, Nuttall, Comas, Borkowski, \& Akai, 2012).

Teenage mothers with high self-esteem have greater confidence to seek social support from health care agencies when the baby is sick as compared to mothers with low self-esteem (McDermott \& Graham, 2005). Concerning maternal- 
images and self- images, teenage mothers feel embarrassed when they must breastfeed their infants, and for fear of gaining weight, they have a tendency to neglect infants (Pungbangkadee, Parisunyakul, Kantaruksa, Sripichyakarn \& Kools, 2013). Easterbrooks, Chaudhuri, Bartlett and Copeman (2010) in their research of parenting skills among young mothers depicted that teenage mothers who show less resilience functioning exhibited less empathy to their children as they would leave their children experiencing maltreatment.

According to Pitso (2013) teenage mothers provide fewer stimulating experiences than do older mothers, thus contributing to later academic difficulties. To show that they are not ready for motherhood, they display higher levels of parenting stress, less affective responsiveness in interactions with their infants than are adult mothers. They do not provide opportunities for affectional exchange, or share emotions inconsistently, leading to increased risk of psychopathology in the child (Branson, Ardington \& Leibbrandt, 2013). Finally, when these children are troublesome and rebellious toward authority figures such as educators or adults in respective communities, they face discrimination and ostracism (Maldonado, 2010), emanating from the cultural belief that they were never welcomed at birth or introduced to the ancestors "imbeleko".

\section{Way Forward}

- Multi - disciplinary approach has a crucial role in successful preventive programme. High degree of cooperation between parents, nurses and teenage mothers must by encouraged.

- For teenage mothers to grow and develop, they need proper mentoring, and basic education which will open the doors to their acquisition of their dream and goals.

- "Young- Mums- to -Be" courses to be delivered at the local clinics and government hospitals to provide intensive support and counseling around issues such as postnatal depression, low self-esteem and destructive family relationships.

- Gender-equality campaigns be organized at local government level to educate males to stop intimate partner violence.

- Condoms at schools, taverns (i.e. shebeens) and during festivals be distributed because they are effective against HIV, STIs and further pregnancies.

- Derogatory remarks to children born to teen-mothers should be avoided as they crystalize hatred and neuroticism in their psychological well-being.

\section{References}

Bhana, D., Morrell, R., Shefer, T., \& Ngabaza, S. (2010). South African teachers' responses to teenage pregnancy and teenage mothers in schools. Culture, health \& sexuality, 12(8), 871-883.

Branson, N., Ardington, C., \& Leibbrandt, M. (2013). Trends in teenage childbearing and schooling outcomes for children born to teens in South Africa.

Brook, W.D, Morajele, N.K, Zhang, C\& Brook, J.S. (2006). South African Adolescents: Pathways to Risky Sexual Behaviour. AIDS Education and Prevention,18(3),259-272

Bryan, A., Kagee, A., \& Broaddus, M. R. (2006). Condom use among South African adolescents: developing and testing theoretical models of intentions and behavior. AIDS and Behavior, 10(4), 387-397.

Carr, A. (2011). Positive Psychology: The science of happiness and human strength. (2nd edition.). Bruner-Routledge: New-York, NY.

Casad, B. J., Marcus-Newhall, A., Nakawaki, B., Kasabian, A. S., \& LeMaster, J. (2012). Younger age at first childbirth predicts mothers' lower economic and psychological well-being later in life. Journal of Family and Economic Issues, 33(4), 421-435.

Chigona, A., \& Chetty, R. (2008). Teen mothers and schooling: Lacunae and challenges. South African Journal of Education, Vol 28 (2), 261-281.

Coley, R. L. \& Chase-Lansdale. (2009). Adolescent pregnancy and parenthood. American Psychologist, 53 (2), 152 - 166

Deci, E.L. \& Ryan, R.M. (2006). Hedonia, Eudaimonia, and Well-Being: An Introduction. Journal of Happiness Studies, (9), 1-11.

De Vos, A. S., Strydom, H., Fouche,C.D, and Delport, C.S.L (2011). Research at Grass Roots: For the social sciences and human services professions. (4 $4^{\text {th }}$ ed.) Van Schaik Publishers: Pretoria

Diener, E., \& Lucas, R.E. (1999). Personality and subjective well-being. In D. Kahneman, E, \& N. Schwarz (Eds.), Well-being: The foundations of hedonic psychology (pp213-229). Russel Sage Foundation: New York, NY.

Dixon-Mueller, R. (2008). How young is "too young"? Comparative perspectives on adolescent sexual, marital, and reproductive transitions. Studies in Family Planning, 39(4), 247-262.

Dunkel, S. C. (2011). Psychological science on pregnancy: stress processes, biopsychosocial models, and emerging research issues. Annual review of psychology, 62 , 531-558.

Dunkle, K., Jewkes, R., Nduna, M., Levin, J., Jama, N., Khuzwayo, N., Koss, M.P., \& Duwury, N. (2006). Perpetration of partner violence and HIV risk behaviour among young men in the rural Eastern Cape. AIDS, (20):2107-2114

Eaton, L., Flisher A.J., \& Aaro, L.E. (2003). Unsafe sexual behaviour in South African Youth. Social Science \& Medicine,Vol.56,149-165.

Ensor, R., \& Hughes, C. (2010). With a little help from my friends: maternal social support, via parenting, promotes willingness to share in preschoolers born to young mothers. Infant and Child Development, 19(2), 127-141.

Epstein, N., Baldwin, L., \& Bishop, D. (1983). The McMaster Family Assessment Device. Journal of Mental and Family Therapy, 9, 171-180.

Flaherty, S. C., \& Sadler, L. S. (2011). A review of attachment theory in the context of adolescent parenting. Journal of Pediatric Health Care, 25(2), 114-121

Formby, E., Hirst, J., Owen, J., Hayter, M., \& Stapleton, H. (2010). 'Selling it as a holistic health provision and not just about condoms...'Sexual health services in school settings: current models and their relationship with sex and relationships education policy and provision. Sex Education, 10(4), 423-435.

Furstenberg, F. F. (2007). Destinies of the disadvantaged: The politics of teen childbearing. New York, NY: Russell Sage. 
Grant, M., \& Hallman, K. (2006). Pregnancy- related school dropout and prior school performance in South Africa. Policy Research Division Working Paper 212. New York: Population Council.

Gustafsson, S. \& Worku, S (2007) "Teenage Motherhood and Long-run Outcomes in South Africa," Tinbergen Institute Discussion Papers 07-024/3, Tinbergen Institute Holborn, L., \& Eddy, G. (2011). First steps to healing the South African Family. South African Institute of Race Relations: Richmond.

Hunter, M. (2007). The changing political economy of sex in South Africa: The significance of unemployment and inequalities to the scale of the AIDS pandemic. Social Science \& Medicine 64: 689-700.

Impett, E., \& Peplau, L.A. (2003). Sexual compliance: Gender, motivational, and relationship perspectives. Journal of Sex Research, 40, 87-100.

IRIN Africa. (2011). South Africa: Teenage pregnancy figures cause alarm. S.A

Jewkes, R., Morrell, R., \& Christofides, N. (2009). Empowering teenagers to prevent pregnancy: Lessons from South Africa. Culture, Health and Sexuality 11: 675-88.

Koen, V. (2009). The parent-adolescent relationship and the emotional well-being of adolescents. [Unpublished Master's thesis]. North-West University, Vaal -Triangle Campus, South Africa.

Koen, V., van Eeden, C., \& Rothmann, S. (2013). Psychological Well-Being of Families in a South African Context: A Prospective Multifactorial Model. Journal of Psychology in Africa, 23(3), 409-418.

Kotzé, M., Visser, M., Makin, J., Sikkema, K., \& Forsyth, B. (2013). Psychosocial variables associated with coping of HIV-positive women diagnosed during pregnancy. AIDS and Behavior, 17(2), 498-507.

Kreager, D. A., Matsueda, R. L., \& Erosheva, E. A. (2010). Motherhood and Criminal Desistance in Disadvantaged Neighborhoods`. Criminology, 48(1), $221-258$.

Leerlooijer, J. N., Bos, A. E., Ruiter, R. A., van Reeuwijk, M. A., Rijsdijk, L. E., Nshakira, N., \& Kok, G. (2013). Qualitative evaluation of the Teenage Mothers Project in Uganda: a community-based empowerment intervention for unmarried teenage mothers. BMC public health, 13(1), 816.

Lehana, T.V., \& van Rhyn, L. (2003). A phenomenological investigation of experiences of pregnancy by unmarried adolescents in Maseru. Health SA Gesondheid : Journal of Interdisciplinary Health Sciences 01/2003;

Louw, D. \& Louw, A. (2007).Child and adolescent development. The University of Free State: Bloemfontein.

Luker, K. (1996). Dubious conceptions: The politics of teen pregnancy. Cambridge, MA: Harvard University Press.

Macleod, C. (2003). Teenage pregnancy and the construction of adolescence scientific literature in South Africa. Rhodes University: Grahamstown, South Africa.

Macleod, C. I. \& Tracy, T. (2010). A decade later: follow-up review of South African research on the consequences of and contributory factors in teen-aged pregnancy. South African Journal of Psychology, 40 (1), 18-31.

Maldonado, S. (2010). Illegitimate Harm: Law, Stigma, and Discrimination Against Nonmarital Children.

Markway, B. \& Markway, G. (2011) Spreading the word about the value of quiet, sensitive people. September 13th.

McDermott, E.,\& Graham, H. (2005). Resilient young mothering: Social inequalities, late modernity and the 'problem' of teenage' motherhood. Joumal of Youth Studies, 8,59-79.

Mkhwanazi, N. (2010). Understanding teenage pregnancy in a post-apartheid South African township. Culture, health \& sexuality, 12(4), $347-358$.

Mothiba, T.M. \& Maputle, M.S., 2012. 'Factors contributing to teenage pregnancy in the Capricorn district of the Limpopo Province'. Curationis 35(1).

Mouton, J.(1996). Understanding social research. Van Schaik Publishers: Pretoria

Ngcwayi, Y. (2013). Eastern Cape's teen pregnancy nightmare. journoz2013.wordpress.com/.../eastern-capes-teen-pregnancy-nightmare

Nzouankeu, A, M (2010). The down side to the government's baby grant. 10 August 2010. SA

Olley, B.O. (2006). Social and health behaviours in youth of the streets of Ibadan, Nigeria. Child Abuse Neglect,30, 271-282

Panday, S., Makiwane, M., Ranchod, C. \& Letsoala, T. (2009) Teenage pregnancy in South Africa: with a specific focus on school-going learners. (Commissioned by UNICEF, July).

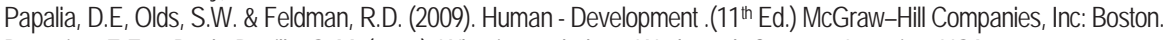

Pastorino, E.E. \& Doyle-Portillo, S. M. (2011). What is psychology. Wadsworth Cengage Learning: USA

Pungbangkadee, R., Parisunyakul, S., Kantaruksa, K., Sripichyakarn, K., \& Kools, S. (2013). Experiences of early motherhood among Thai adolescents: Perceiving conflict between needs as a mother and an adolescent. Pacific Rim International Journal of Nursing Research, 12(1), 70-82.

Richter, L., Komárek, A., Desmond, C., Celentano, D., Morin, S., Sweat, M., \& Coates, T. (2013). Reported physical and sexual abuse in childhood and adult HIV risk behaviour in three African countries: findings from Project Accept (HPTN-043). AIDS and Behavior, 1-9.

Rose, S. D. (2013). Challenging Global Gender Violence. Procedia-Social and Behavioral Sciences, 82, 61-65.

Ryff,C.D. \& Keyes,C.L.M (1995). The structure of psychological well-being revised.Journal of Personality and Social psychology, 69 (4), $719-727$.

Sadock, B.J. \& Sadock ,V.A. (2003). Synopsis of psychiatry . Behavioural sciences/clinical psychiatry . (9th Edition). Lippincott Williams and Wilkins: USA

SALDRU UCT. (2009). Measuring concurrent partnerships: Potential for under-estimation in UNAIDS recommend method. Volume 25. Issue 12.Cape Town, South Africa.

Sodi, E. (2009). The experiences of teenage mothers: A phenomenological investigation. Journal of the Psychology Resource Center, University of Western Cape, 9 (2), 1-9

Valentino, K., Nuttall, A. K., Comas, M., Borkowski, J. G., \& Akai, C. E. (2012). Intergenerational Continuity of Child Abuse Among Adolescent Mothers Authoritarian Parenting, Community Violence, and Race. Child maltreatment, 17(2), 172-181.

Van Eijk, R.T., (2007). Factors contributing to teenage pregnancies in Rarotonga. United Nations Population Fund (UNFPA): Avarua.

Woan, J., Lin, J., \& Auerswald, C. (2013). The health status of street children and youth in low-and middle-income countries: a systematic review of the literature. Journal of Adolescent Health.

Umberson, D., Pudrovska, T., \& Reczek, C. (2010). Parenthood, Childlessness, and Well-Being: A Life Course Perspective. Joumal of Marriage and Family, 72(3), 612-629.

Pitso, J.T. (2013). Pregnant Teenagers Readiness For Motherhood: A Quantitative Investigation In Nkonkobe Municipality, Eastern Cape. [Published M.Soc. Sc Thesis]. University of Fort Hare: Alice.

Theron, L \& Dunn, N. (2006). Coping strategies for adolescent birth-mothers who return to school following adoption. South African Joumal of Education, Vol 26(4)491-499

Vlassoff, M., Shearer, J., Walker, D., \& Lucas, H. (2008). Economic impact of unsafe abortion-related morbidity and mortality: evidence and estimation challenge. Institute of Development Studies. . Vol. 59.

Willan, S. (2013). A Review of Teenage Pregnancy in South Africa- Experiences of schooling, and Knowledge and Access to Sexual\& Reproductive Health Services. Health System Trust: South Africa.

Wilson, W. J. (1987). The truly disadvantages: The inner city, the underclass, and public policy. Chicago, IL: University of Chicago Press.

Wong, J., \& Checkland, D. (1999). Introduction. In J. Wong \& D. Checkland (Eds.), Teen pregnancy and parenting (pp. 13-23). Buffalo, NY: University of Toronto.

World Health Organization (WHO). (2006). HIV prevention and treatment guidelines. Antiretroviral drugs for treating pregnant women and preventing HIV infection in infants, towards universal access: recommendations for a public health approach. Geneva, World Health Organization.

Zapata, L. B., Kissin, D. M., Bogoliubova, O., Yorick, R. V., Kraft, J. M., Jamieson, D. J., \& Hillis, S. D. (2013). Orphaned and abused youth are vulnerable to pregnancy and suicide risk. Child abuse \& neglect.

Zimmer- Gembeck, M., \& Locke, E.M. (2007). The Socialization of adolescent coping behaviours: Relationships with families and teachers. Journal of Adolescence, Volume 30 (1), 1-16.

Ziyane, I.S. \& Ehlers, V.J. (2006). Swazi youth attitudes and perceptions concerning adolescents' pregnancies and contraception. Health S.A. Gesondheid, 11(1):31-42. 